\title{
Substituted ALPO-5 Zeolites as Promising O2 Sorption Pump Materials: A Density Functional Theory Study
}

Steven A. Wilson ${ }^{1}$, Ellen B. Stechel ${ }^{2}$, Ivan Ermanoski ${ }^{3}$, Christopher L. Muhich ${ }^{1 *}$

${ }^{1}$ Chemical Engineering, School for the Engineering of Matter, Transport, \& Energy, Arizona State University, 551 E. Tyler Mall, Tempe Arizona, 85287, USA

${ }^{2}$ ASU LightWorks ${ }^{\circledR}$ and School of Molecular Sciences, Arizona State University, PO Box 875402, Tempe Arizona, 85287-5402, USA

${ }^{3}$ ASU LightWorks ${ }^{\circledR}$ and School of Sustainability, Arizona State University, PO Box 875402, Tempe Arizona, 85287-5402, USA

* Corresponding Author

\section{Supplemental Information}
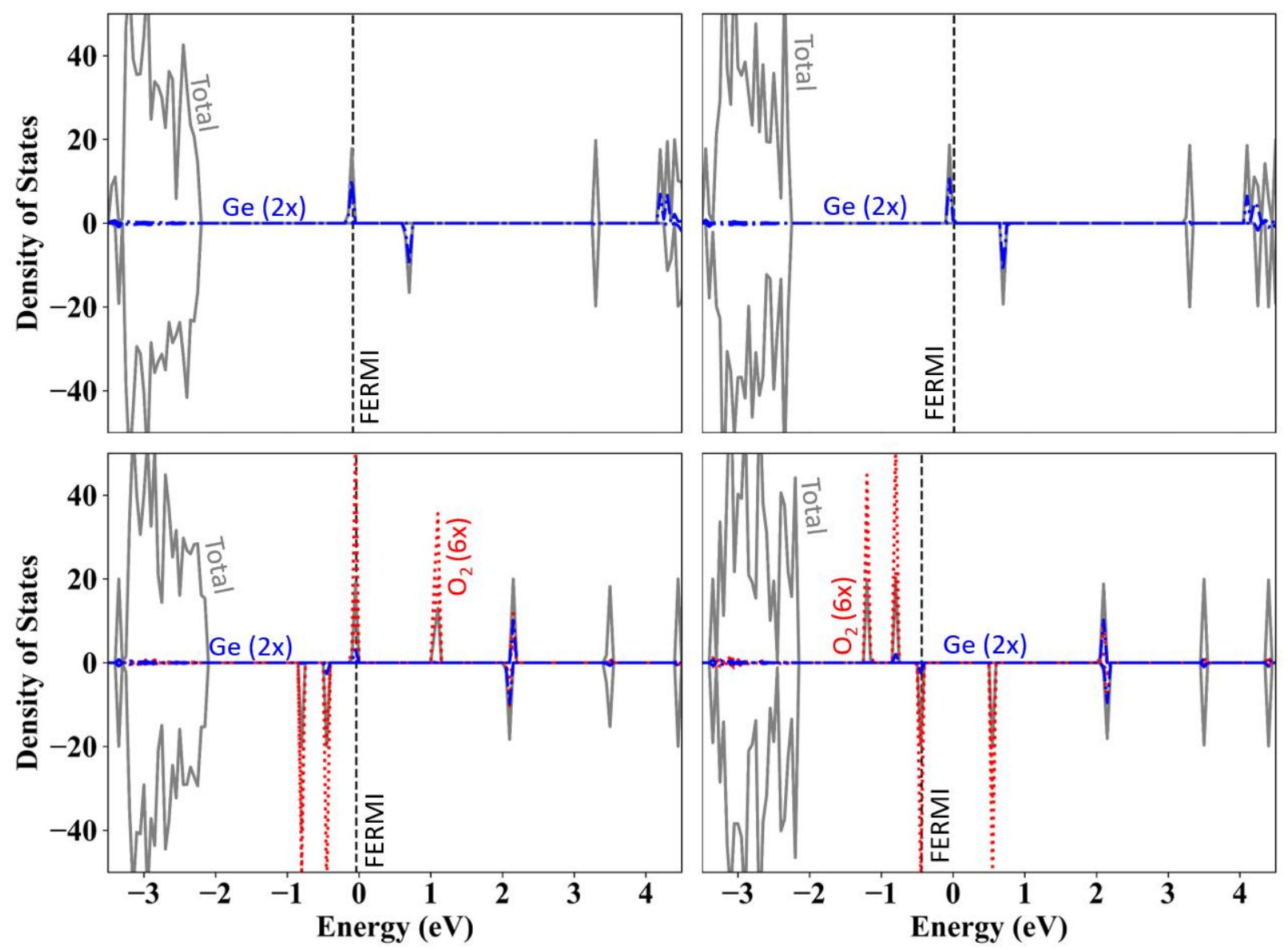

Figure S1: DOS plots for Ge in site 3 (left) and site 4 (right) for the no $\mathrm{O}_{2}$ environment (top) and adsorbed $\mathrm{O}_{2}$ environment (bottom). 

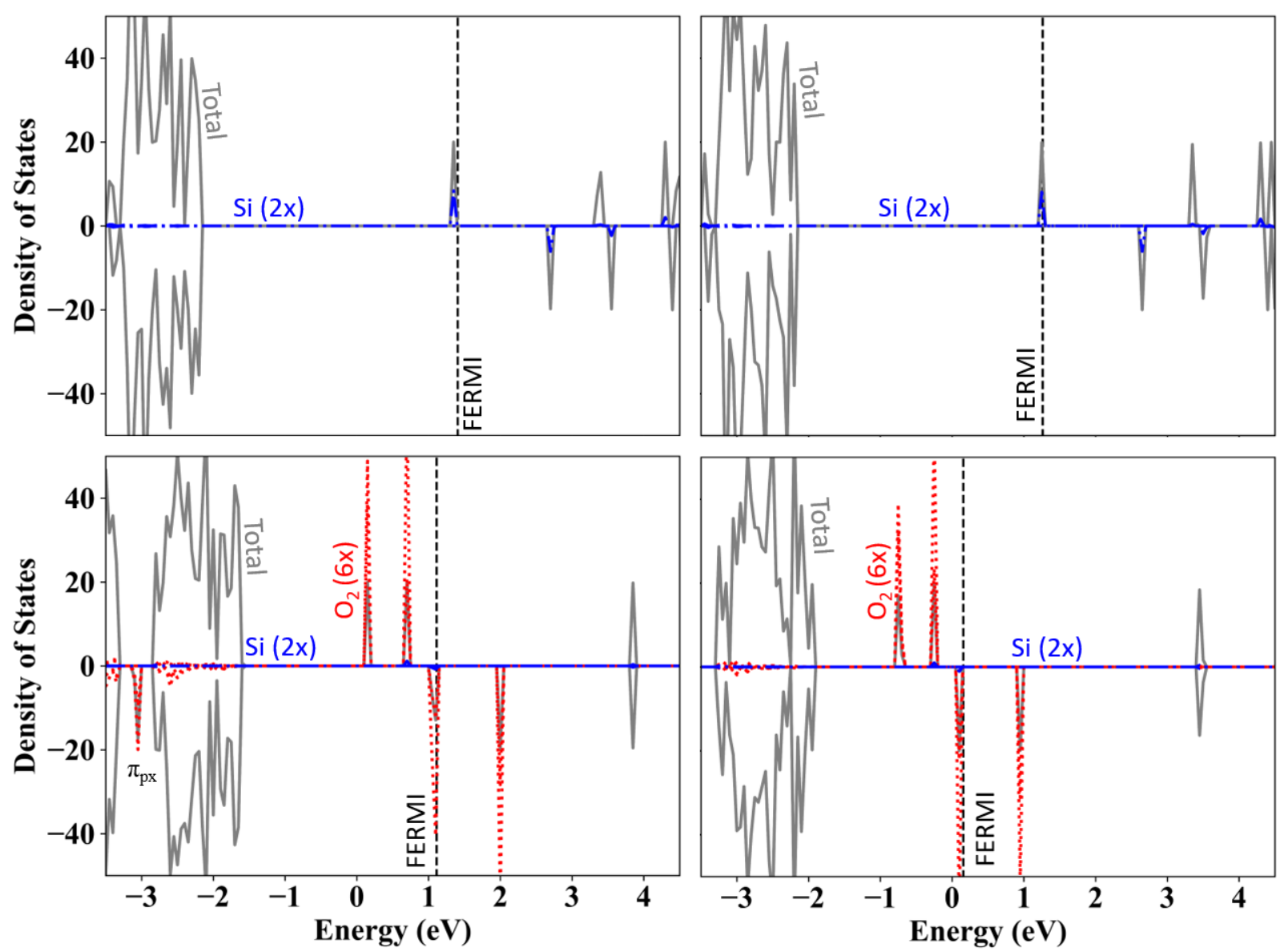

Figure S2: DOS plots for $\mathrm{Si}$ in site 3 (left) and site 4 (right) for the no $\mathrm{O}_{2}$ environment (top) and adsorbed $\mathrm{O}_{2}$ environment (bottom). 

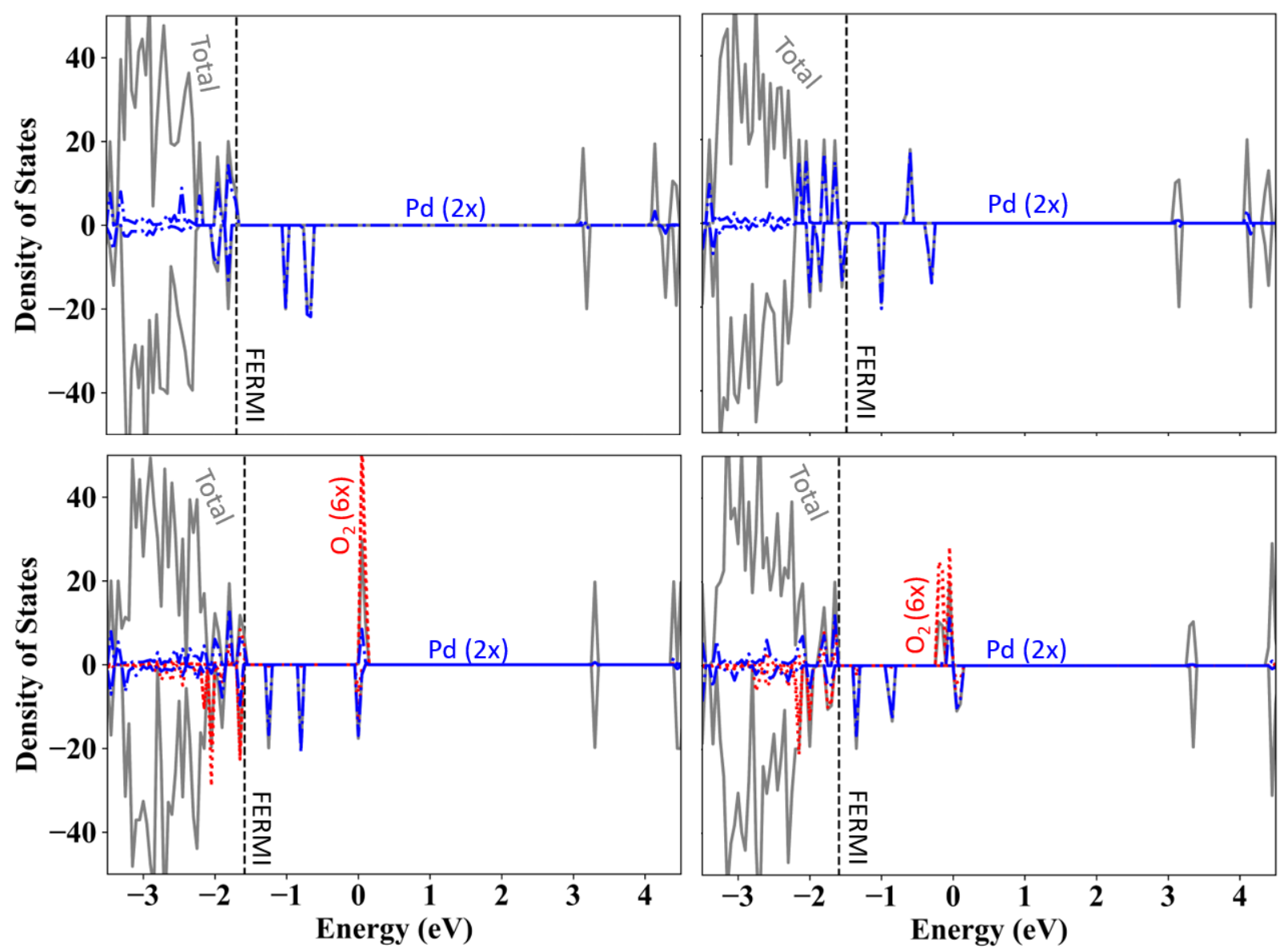

Figure S3: DOS plots for Pd in site 3 (left) and site 4 (right) for the no $\mathrm{O}_{2}$ environment (top) and adsorbed $\mathrm{O}_{2}$ environment (bottom). 

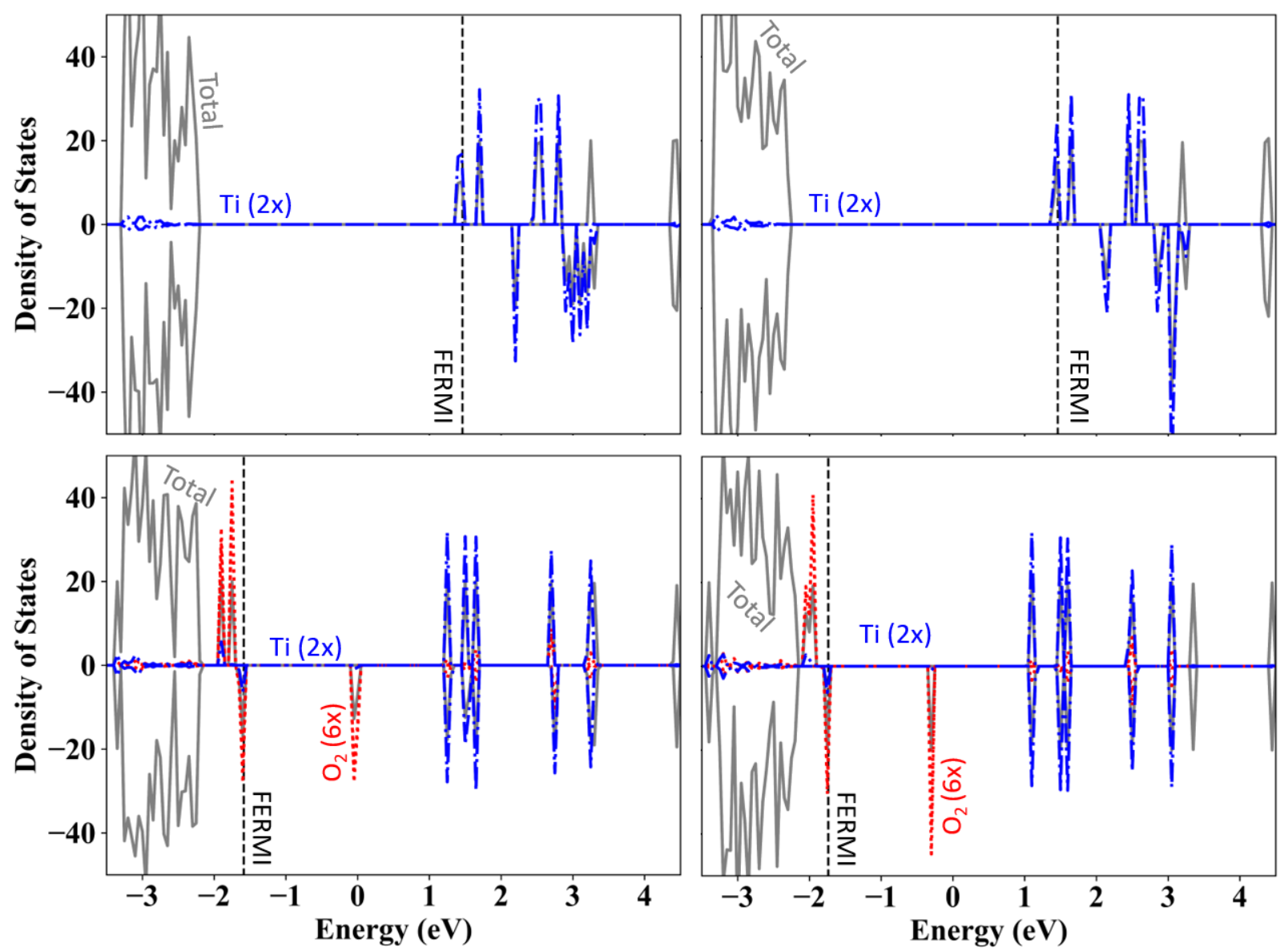

Figure S4: DOS plots for Ti in site 3 (left) and site 4 (right) for the no $\mathrm{O}_{2}$ environment (top) and adsorbed $\mathrm{O}_{2}$ environment (bottom). 

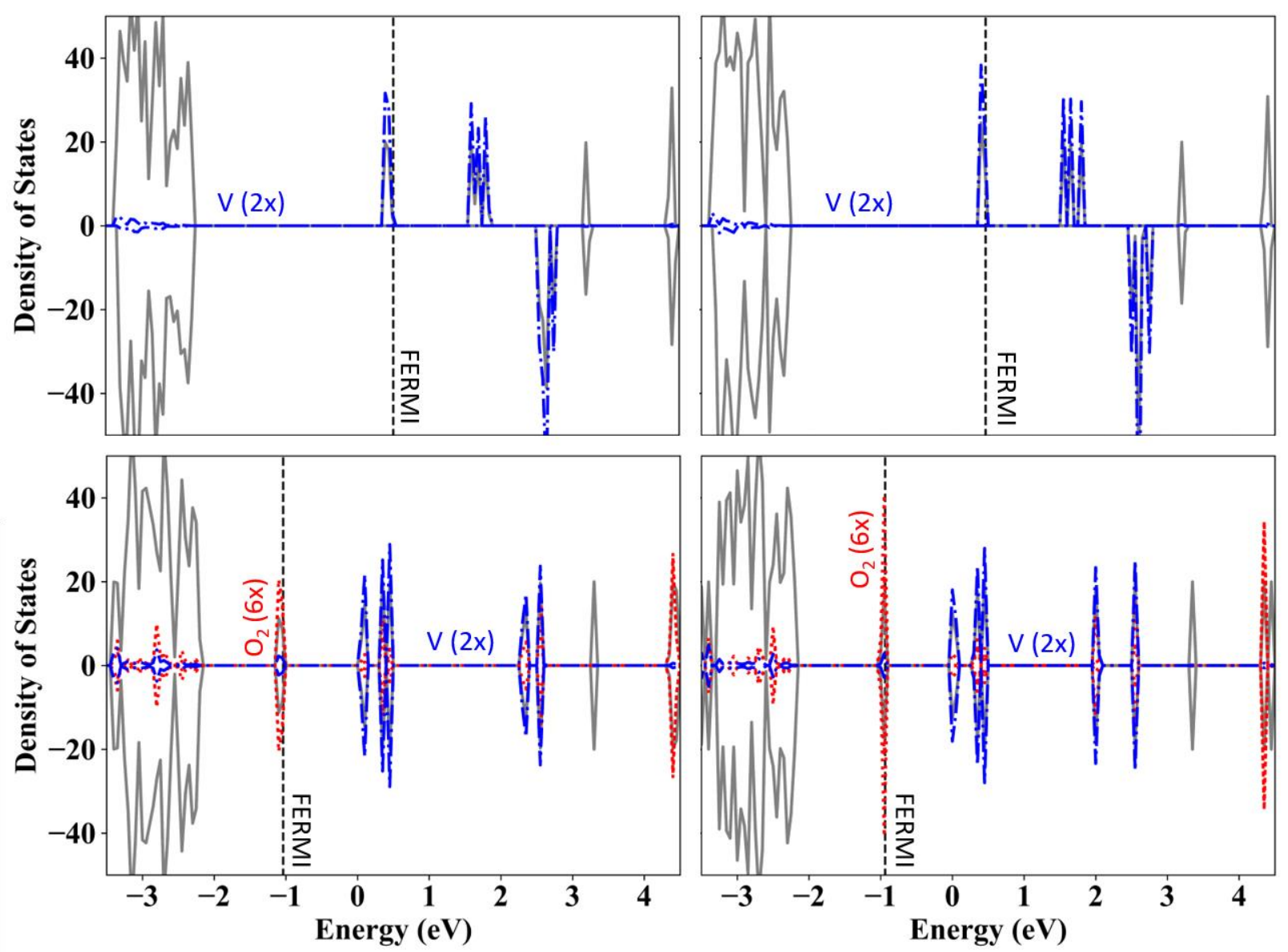

Figure S5: DOS plots for $\mathrm{V}$ in site 3 (left) and site 4 (right) for the no $\mathrm{O}_{2}$ environment (top) and adsorbed $\mathrm{O}_{2}$ environment (bottom). 

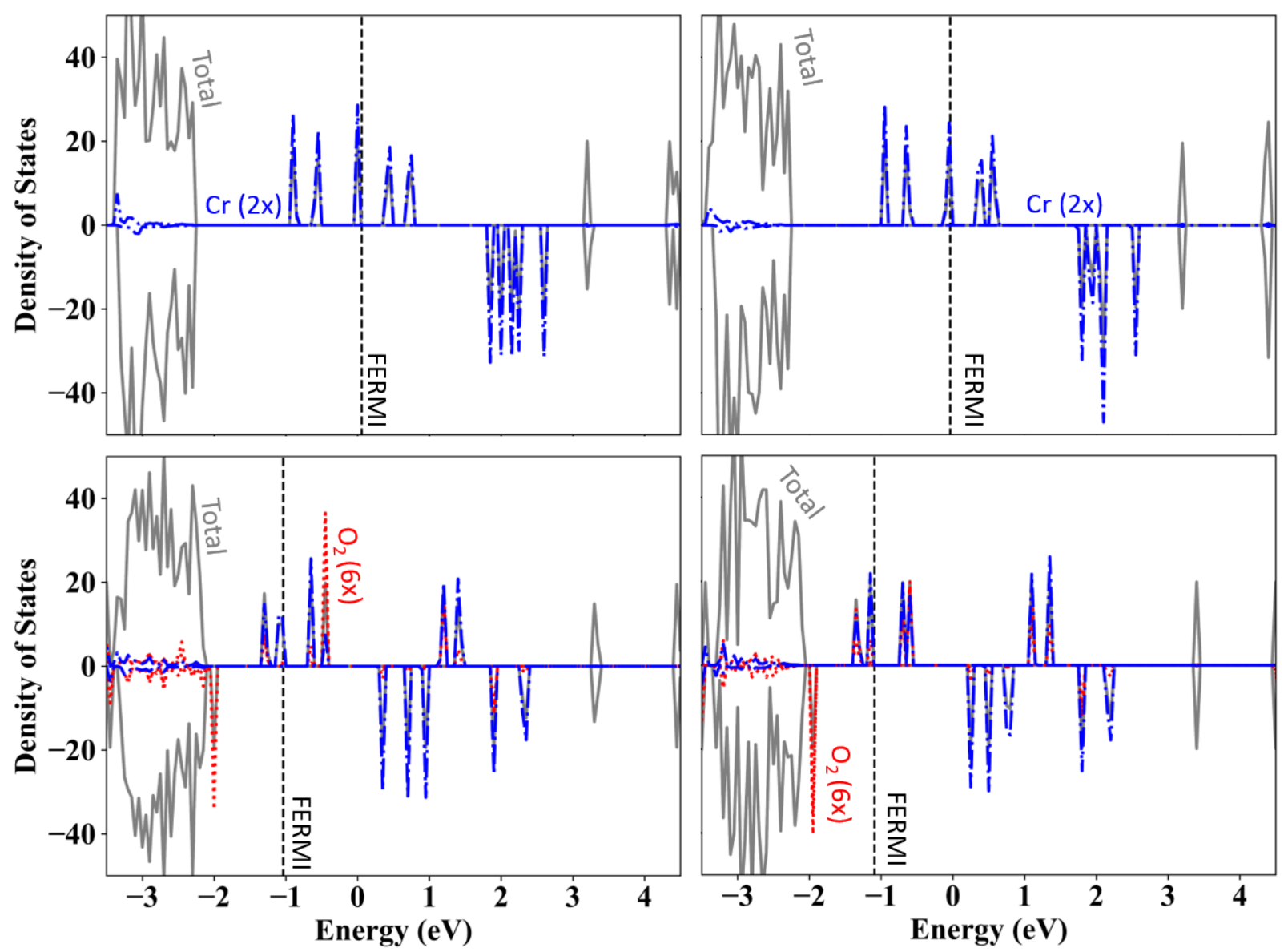

Figure S6: DOS plots for Cr in site 3 (left) and site 4 (right) for the no $\mathrm{O}_{2}$ environment (top) and adsorbed $\mathrm{O}_{2}$ environment (bottom). 

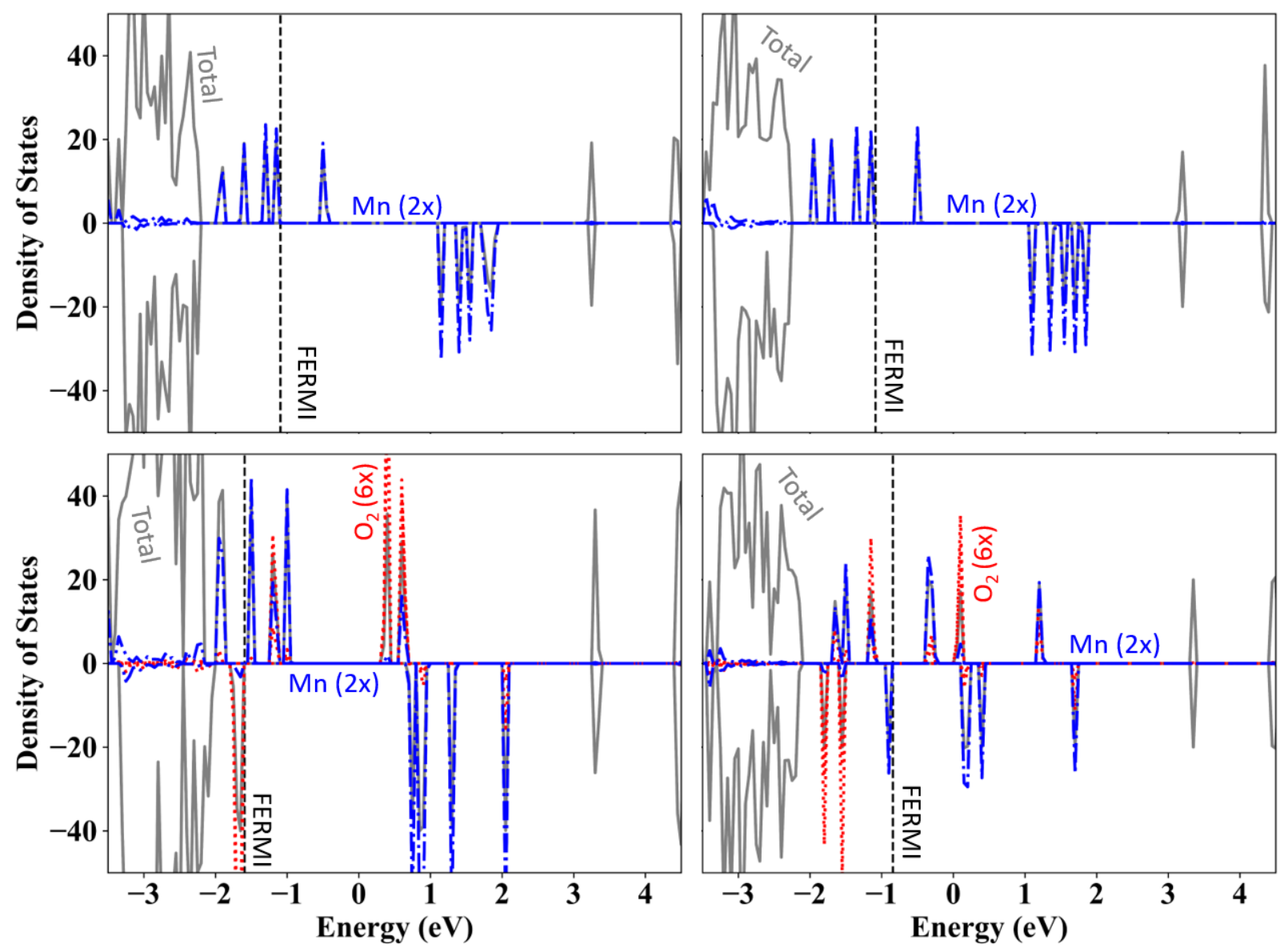

Figure S7: DOS plots for Mn in site 3 (left) and site 4 (right) for the no $\mathrm{O}_{2}$ environment (top) and adsorbed $\mathrm{O}_{2}$ environment (bottom). 

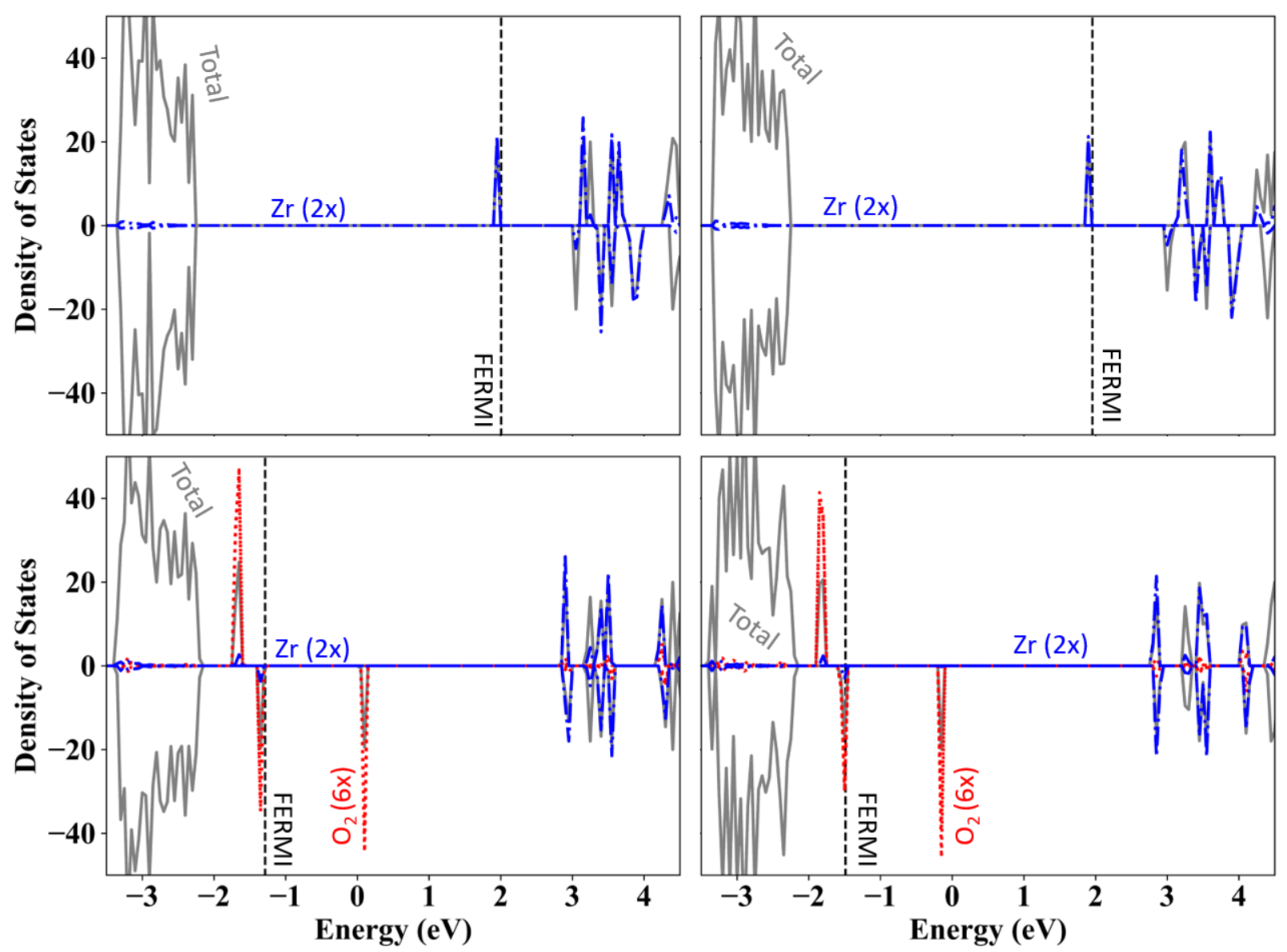

Figure S8: DOS plots for $\mathrm{Zr}$ in site 3 (left) and site 4 (right) for the no $\mathrm{O}_{2}$ environment (top) and adsorbed $\mathrm{O}_{2}$ environment (bottom). 

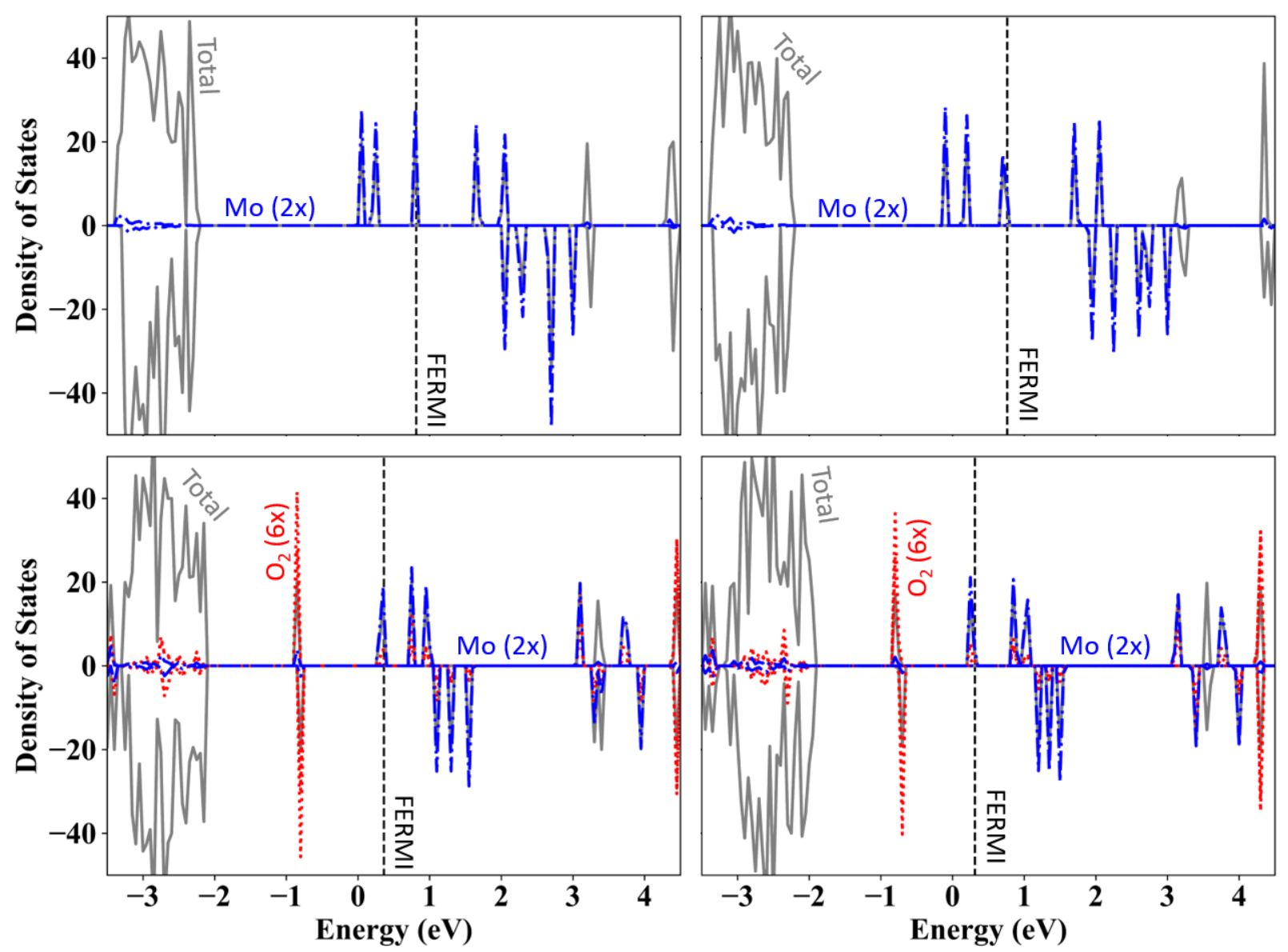

Figure S9: DOS plots for Mo in site 3 (left) and site 4 (right) for the no $\mathrm{O}_{2}$ environment (top) and adsorbed $\mathrm{O}_{2}$ environment (bottom). 

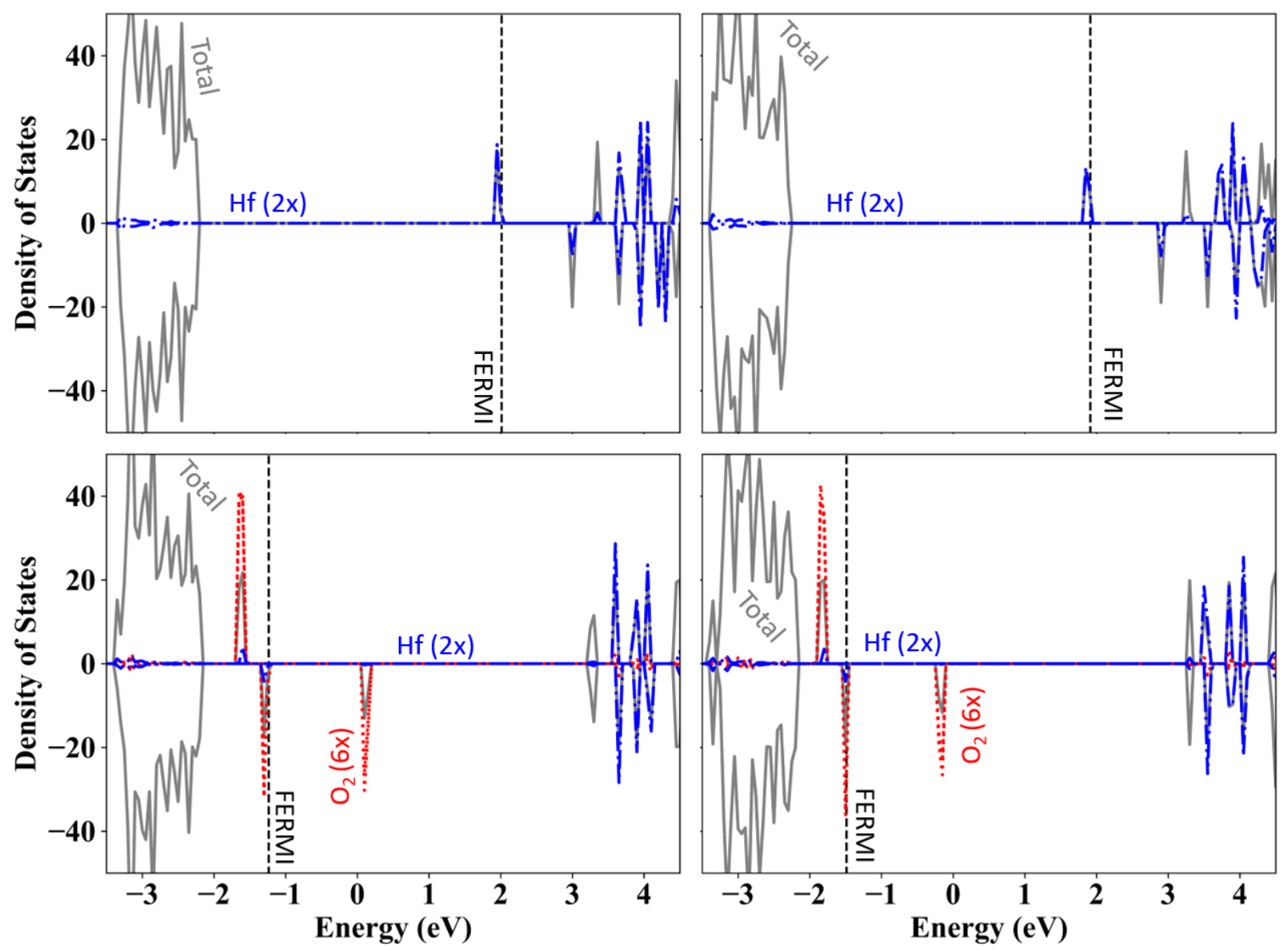

Figure S10: DOS plots for $\mathrm{Hf}$ in site 3 (left) and site 4 (right) for the no $\mathrm{O}_{2}$ environment (top) and adsorbed $\mathrm{O}_{2}$ environment (bottom). 

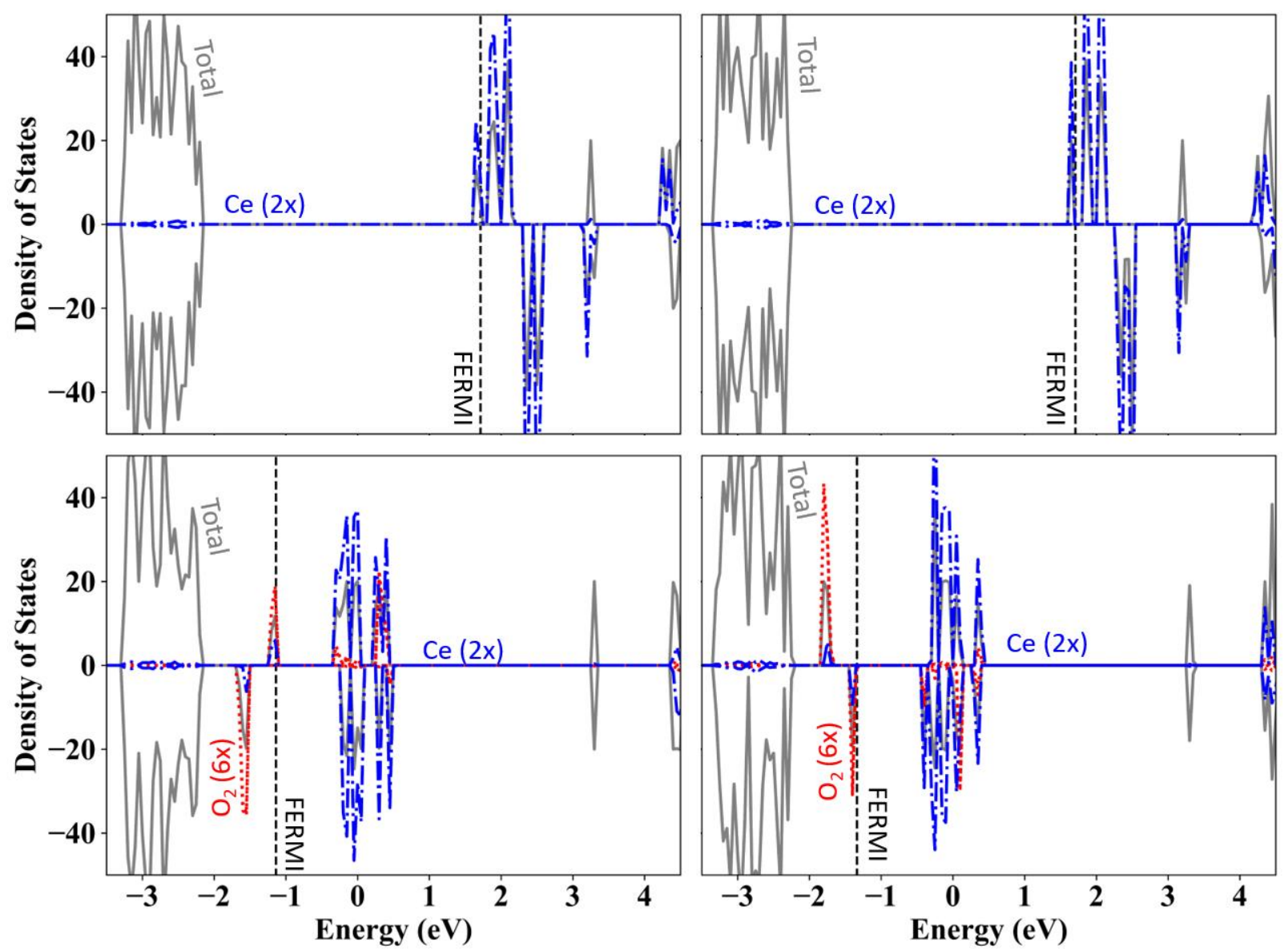

Figure S11: DOS plots for Ce in site 3 (left) and site 4 (right) for the no $\mathrm{O}_{2}$ environment (top) and adsorbed $\mathrm{O}_{2}$ environment (bottom). 

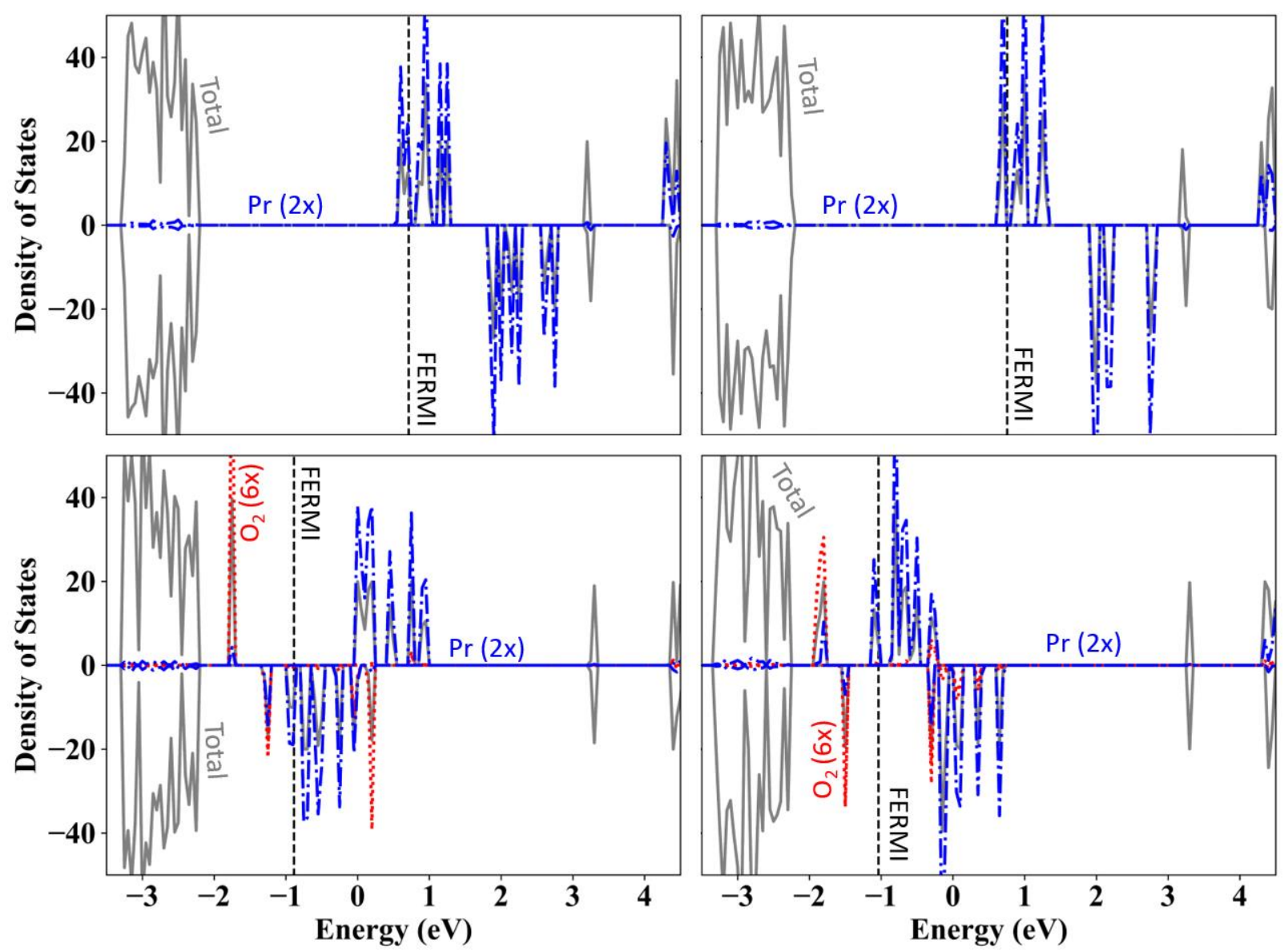

Figure S12: DOS plots for Pr in site 3 (left) and site 4 (right) for the no $\mathrm{O}_{2}$ environment (top) and adsorbed $\mathrm{O}_{2}$ environment (bottom). 


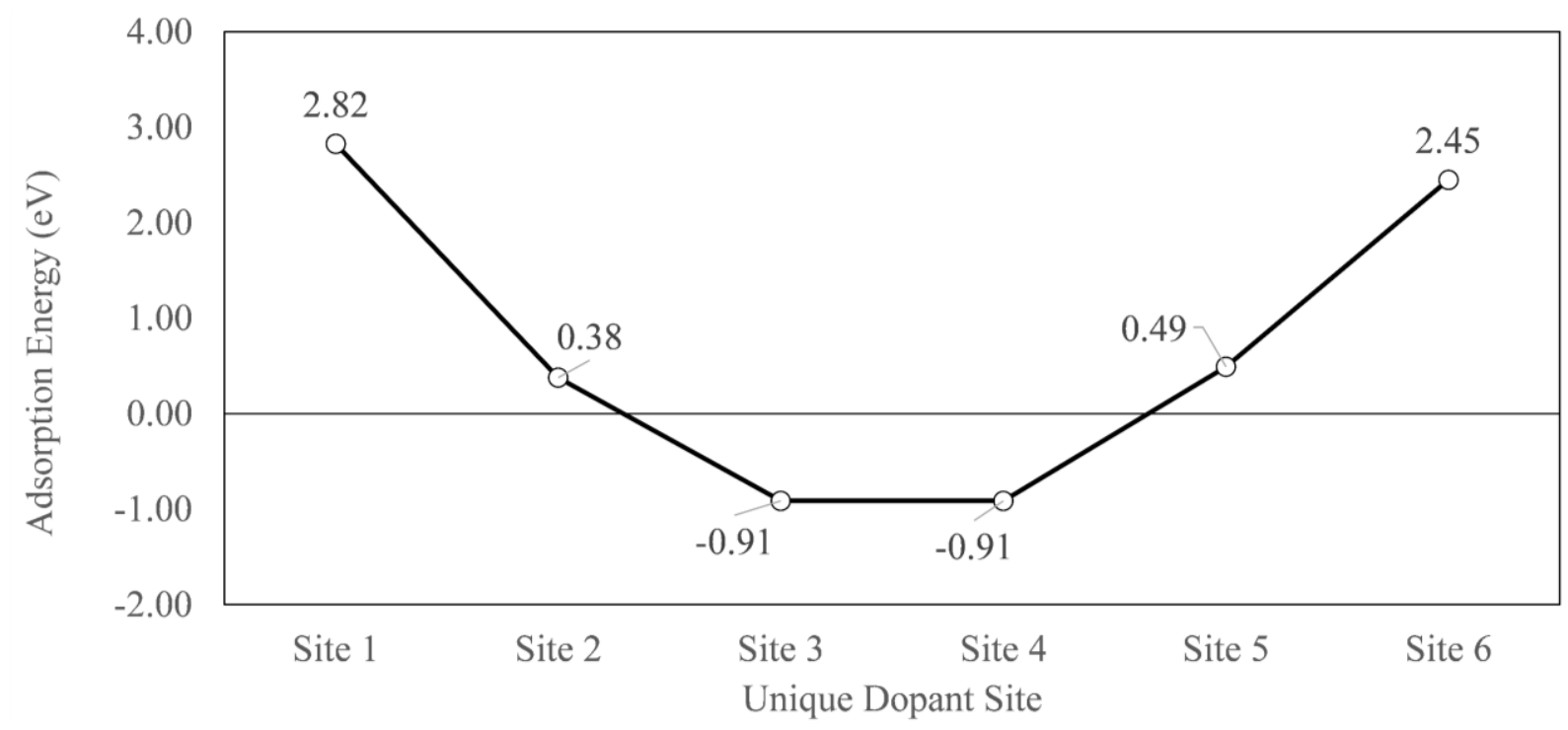

Figure S13: Adsorption energy analysis for Pt substituted sites 1-6. Negative (-) energy relates to exothermic process.

Table S1: Bader charge analysis of for $\mathrm{O}_{2}$ adsorption to Co.

\begin{tabular}{|c|ccc|}
\hline & No O2 & O2 in Void & O2 near Co \\
\hline Fermi Energy (eV) & -1.06 & -0.99 & 0.11 \\
Co Bader CHG (eV) & 7.44 & -0.02 & -0.03 \\
Moelculer O Atom1 & & & \\
Bader $\Delta$ CHG (eV) & $6.08^{*}$ & 0.05 & 0.05 \\
$\begin{array}{c}\text { Moleculer O Atom2 } \\
\text { Bader } \Delta \text { CHG (eV) }\end{array}$ & $5.94 *$ & -0.03 & -0.06 \\
Zeolite Lattice O Atom \\
$8 \Delta$ CHG (eV)
\end{tabular}



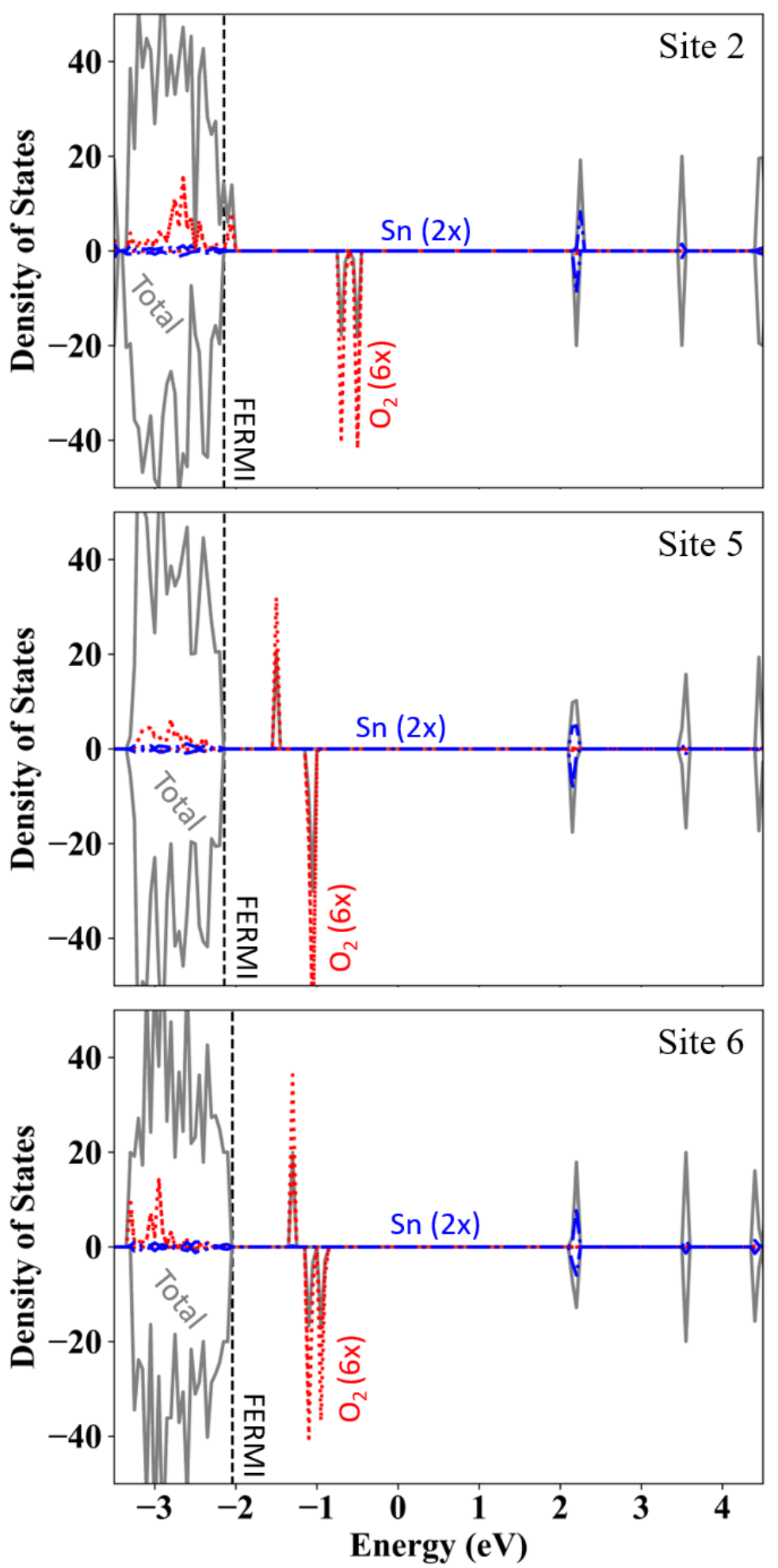

Figure S14: Dos of Sn replacing P in sites 2, 5, and 6. 

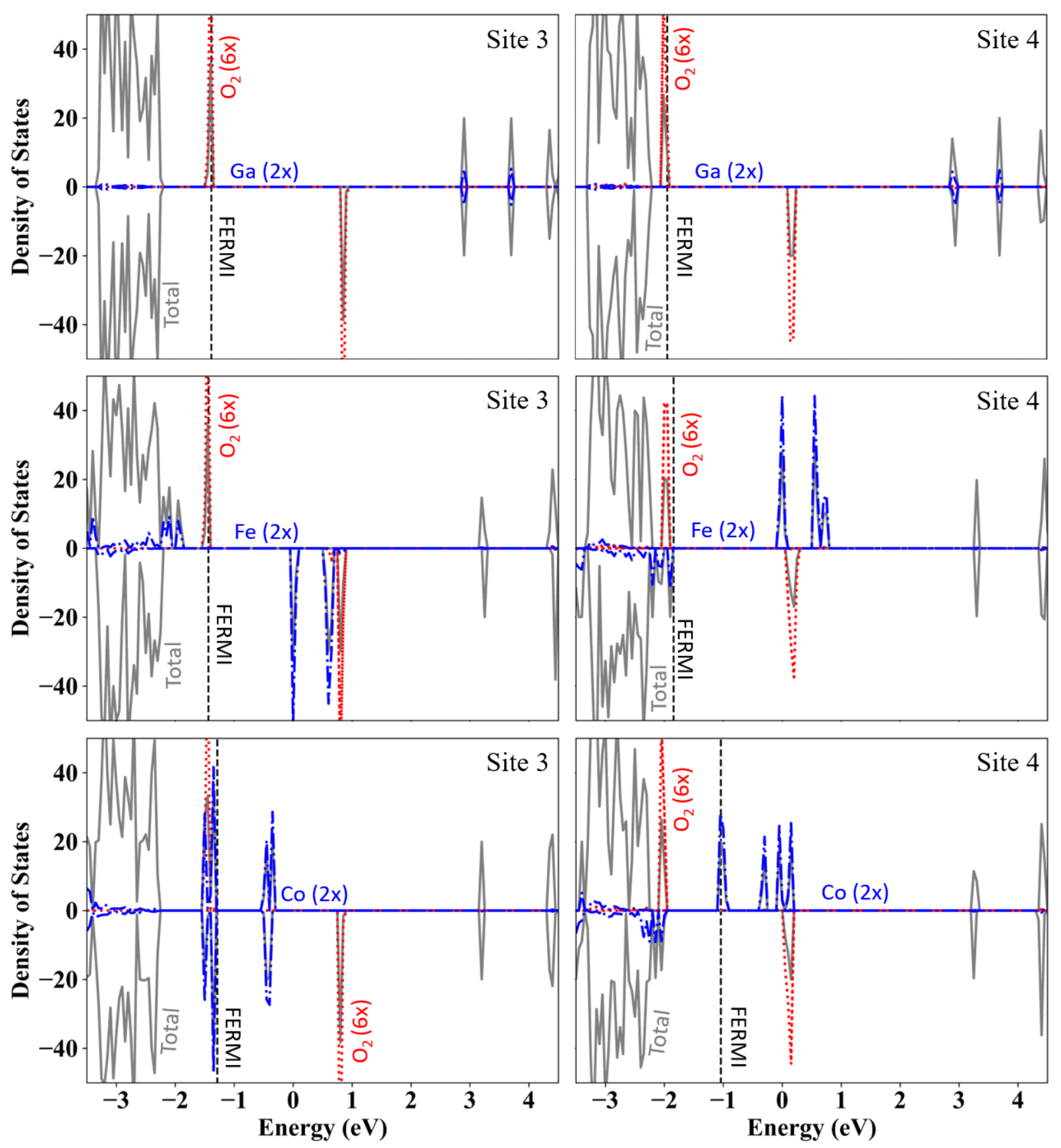

Figure S15: DOS plots for non-binding elements Ga, Fe, and Co in site 3 (left) and site 4 (right) for $\mathrm{O}_{2}$ that has relaxed away from the substitution. 

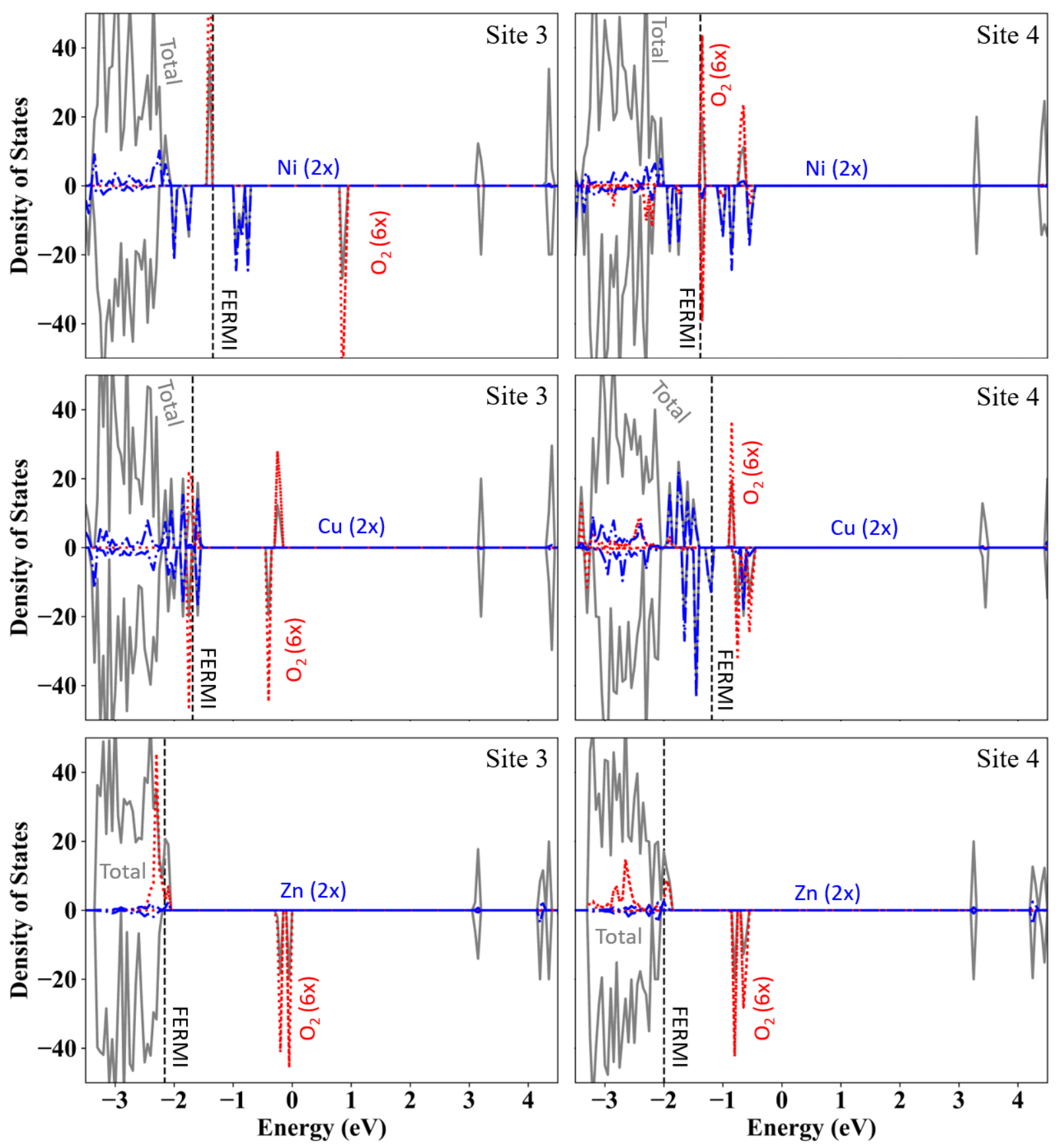

Figure S16: DOS plots for non-binding elements Ni, co, Zn in site 3 (left) and site 4 (right) for $\mathrm{O}_{2}$ that has relaxed away from the substitution. 


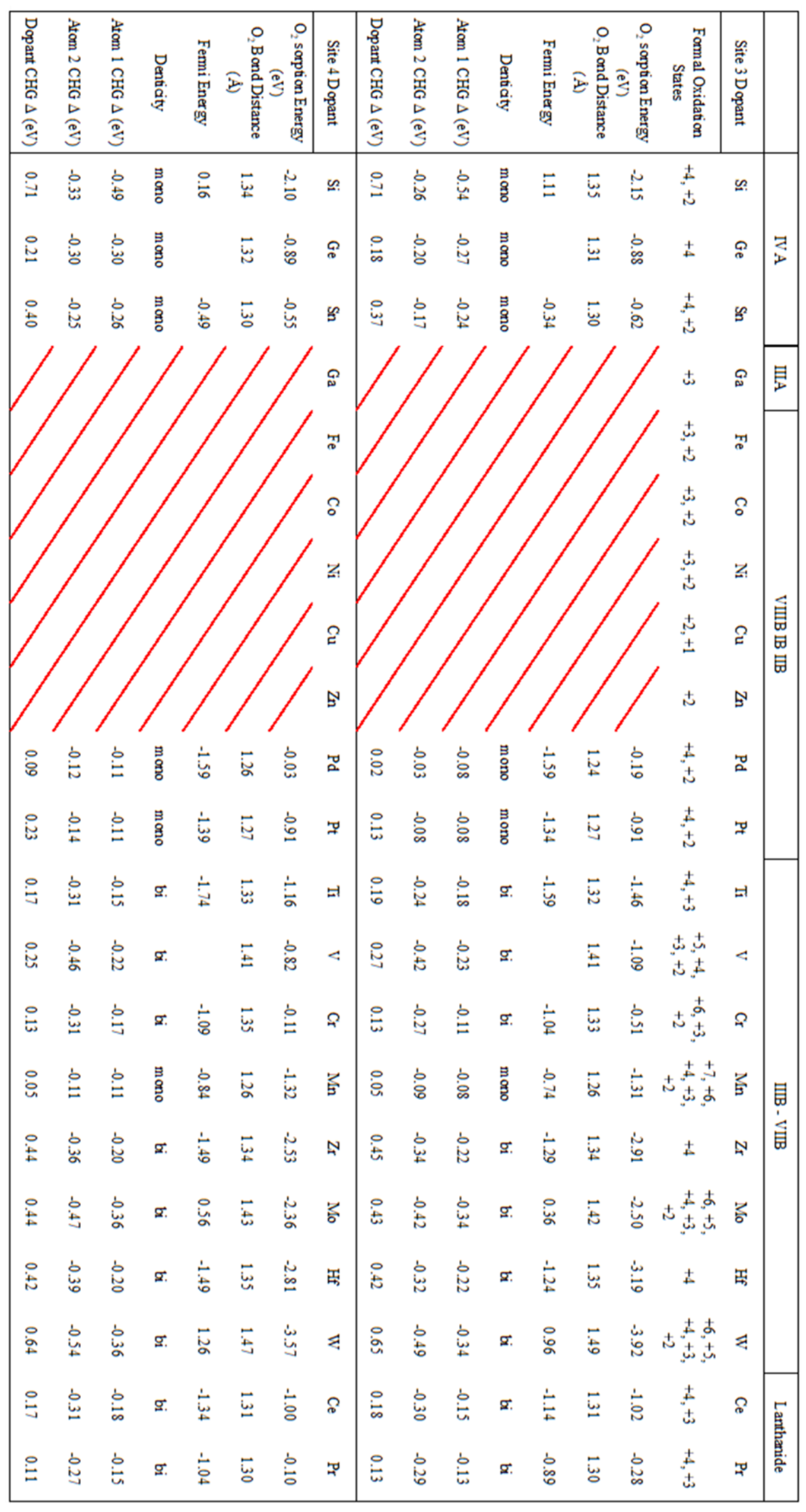

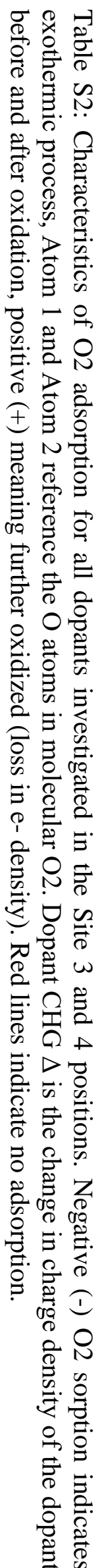

